University of Wollongong

Research Online

Faculty of Engineering - Papers (Archive)

Faculty of Engineering and Information

Sciences

$1-1-2012$

\title{
Precipitation behavior of magnetite in oxide scale during cooling of microalloyed low carbon steel
}

\author{
Xianglong $\mathrm{Yu}$ \\ University of Wollongong, xly991@uowmail.edu.au \\ Zhengyi Jiang \\ University of Wollongong, jiang@uow.edu.au \\ Daijun Yang \\ Shougang Research Institute of Technolgy, China \\ Dongbin Wei \\ University of Wollongong, dwei@uow.edu.au \\ Quan Yang \\ University of Science and Technology Beijing
}

Follow this and additional works at: https://ro.uow.edu.au/engpapers

Part of the Engineering Commons

https://ro.uow.edu.au/engpapers/5278

\section{Recommended Citation}

Yu, Xianglong; Jiang, Zhengyi; Yang, Daijun; Wei, Dongbin; and Yang, Quan: Precipitation behavior of magnetite in oxide scale during cooling of microalloyed low carbon steel 2012, 249-254.

https://ro.uow.edu.au/engpapers/5278

Research Online is the open access institutional repository for the University of Wollongong. For further information contact the UOW Library: research-pubs@uow.edu.au 


\title{
Precipitation behavior of magnetite in oxide scale during cooling of microalloyed low carbon steel
}

\author{
Xianglong $\mathrm{Yu}^{1, \mathrm{a}}$, Zhengyi Jiang ${ }^{1, \mathrm{~b}}$, Daijun $\mathrm{Yang}^{2, \mathrm{c}}$, Dongbin $\mathrm{Wei}^{1, \mathrm{~d}}$ \\ and Quan Yang ${ }^{3, e}$ \\ ${ }^{1}$ School of Mechanical, Materials and Mechatronic Engineering, University of Wollongong, \\ Wollongong NSW 2522, Australia \\ ${ }^{2}$ Shougang Research Institute of Technology, Shougang Group, Beijing, 100043, China \\ ${ }^{3}$ Engineering Research Institute, University of Science and Technology Beijing, Beijing 100083, \\ China \\ axly991@uow.edu.au, bJiang@uow.edu.au, cd.oyang@yahoo.com, ddwei@uow.edu.au, \\ eyangquan@nercar.ustb.edu.cn
}

Keywords: Oxide scale, Wustite decomposition, Magnetite precipitation, Hot-rolled steel strip

\begin{abstract}
Precipitation behavior of magnetite particles in the thermal grown oxide scale during isothermal cooling of microalloyed low carbon steel was studied using scanning electron microscopy (SEM) and thin film X-ray. The oxide scale was generated from Gleeble 3500 Thermal-Mechanical Simulator connected with a humid air generator, to simulate 550 and $450^{\circ} \mathrm{C}$ isothermal treatments. Several types of magnetite precipitates were observed during different cooling processes with respect to the possible mechanisms of precipitation have been discussed. It is found that magnetite particles is as a result of pro-eutectoid precipitation from oxygen-rich wustite, and also as a product of the partial decomposition of wustite during the cooling process due to change of oxygen concentration and migration of iron ions. Furthermore, microalloyed elements in steel reduce the stability of wustite thereby facilitate the precipitation process, whose products of multi-phase oxide finally determine the adhesive strength of oxide scale and steel substrate.
\end{abstract}

\section{Introduction}

Hot-rolled steel strips are inevitably covered with the oxide scale due to thermal oxidation [1, 2], whose thickness and microstructure depend appreciably upon cooling conditions at the exit of the last finishing stand of the rolling mill and upon the type of steel strips. Generally, the tertiary scale formed at finishing temperature (FT) is composed of three well defined layers (iron oxides), namely: a thick wustite (approximate composition $\mathrm{FeO}$ ) layer adjacent to the steel substrate, then an intermediate magnetite $\left(\mathrm{Fe}_{3} \mathrm{O}_{4}\right)$ layer, and finally a thin outermost hematite $\left(\mathrm{Fe}_{2} \mathrm{O}_{3}\right)$ layer [3-5]. Since wustite is unstable below $570^{\circ} \mathrm{C}$ at a eutectoid point of Fe-O system as shown in Fig. 1 [6] under a certain cooling rate the oxide scale is thermodynamically decomposed more or less into a mixture of iron and magnetite by a eutectoid reaction [7], even though it may be possible not to be decomposed under a rapid cooling [8]. In the oxide scale on commercially produced steel strips, the precipitation of magnetite appears not only in the oxygen-rich area near the magnetite-wustite interface during partial decomposition of the wustite at the ambient temperature, but also at the wustite-substrate interface of the adherent oxide scales, which is called magnetite seam in Fig. 2 [9, 10].

However, preferential magnetite precipitates in the iron-rich area near the metal substrate seem highly improbable in the light of the iron-rich wustite is more stable than that of oxygen-rich [8]. Hence, some hypotheses concerning the mechanism behind the formation of magnetite have been presented $[8,10]$. In general, the precipitation of magnetite particles in epitaxy with the wutite is formed as a consequence of oxygen penetration under the oxide scale or of localised nucleation of the decomposition of wustite during cooling process. Furthermore, the possible mechanisms are provided referring to the prior precipitation of iron below $570^{\circ} \mathrm{C}$ [10] or other effects such as impurities in the metal substrate, over-oxidation at the interface by decohesion [2], stress-induced nucleation of magnetite particles or the presence of carbon in the steel [8]. 


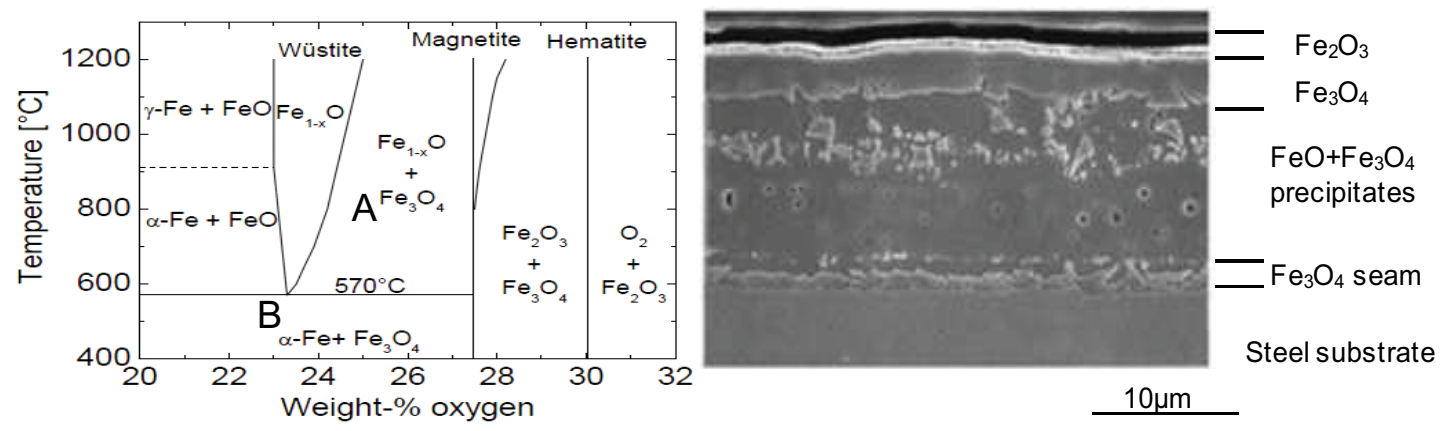

Fig. 1 Fe-O equilibrium phase diagram Fig. 2 Microstructure of oxide scale with magnetite seam

Thus, more possible explanation of magnetite precipitation during the cooling of hot-rolled steel strips: due to the super cooling employed after hot rolling, the cooling rates of oxide scale are fast enough to suppress wustite decomposition above $480^{\circ} \mathrm{C}$, around which the decomposition of wustite proceeds most rapidly [7], but allow it to decompose partially at a low temperature after coiling. Magnetite particles may therefore appear in the wustite layer, as a result of pro-eutectoid precipitation from oxygen-rich wustite, and also as a product of the partial decomposition of wustite.

In this study, an experiment for investigating the development of oxide scale during laminar cooling after hot rolling was conducted in Gleeble 3500 system equipped with a humid air generator. An attempt to clarify the validity of the hypothesis about precipitation of magnetite particles in epitaxy wustite, with particular emphasis on the conditions, temperature and duration during decomposition treatments, has been established. According to the examination of microstructure and morphology of the oxide scale associated with this phenomenon, the corresponding formation mechanism of magnetite seam is also discussed.

\section{Experimental}

Materials. The material used in this experiment was commercial hot-rolled strips from microalloyed low carbon steel for automobiles, with the dimension $120 \mathrm{~mm} \times 25 \mathrm{~mm} \times 5 \mathrm{~mm}$. The chemical composition of the samples is listed in Table 1.

Table 1 Chemical composition of commercial hot-rolled steel strip [wt. \%]

\begin{tabular}{ccccccccc}
\hline $\mathrm{C}$ & $\mathrm{Si}$ & $\mathrm{Mn}$ & $\mathrm{P}$ & $\mathrm{S}$ & $\mathrm{Al}$ & $\mathrm{V}$ & $\mathrm{Nb}$ & $\mathrm{Ti}$ \\
\hline 0.1 & 0.16 & 1.4 & 0.012 & 0.005 & 0.080 & 0.004 & 0.021 & 0.002
\end{tabular}

Sample preparation. The specimens prepared for oxidation test were ground using SiC paper of 2400 mesh to the surface finish of $0.6 \mu \mathrm{m}$, degreased in acetone in an ultrasonic cleaner, washed in water, cleaned in ethanol, then dried immediately before testing. The thermal couple was welded at the centre of the specimen, which will be set into the chamber of Gleeble 3500, Thermal-Mechanical Simulator connected with a humid air generator $[11,12]$. The experimental setup of the chamber with specimen and thermal couple position are illustrated in Fig. 3.

As shown in Fig. 4, the thermo-cycle routine was employed to conduct the high-temperature oxidation of steel strips. Correspondingly, each sample was heated to $900^{\circ} \mathrm{C}$ at $10^{\circ} \mathrm{C} / \mathrm{s}$ and held for $120 \mathrm{~s}$ in the atmosphere of argon. Temperature was decreased to $800^{\circ} \mathrm{C}$, dry air was released for $30 \mathrm{~s}$, and then humid air was released and kept flowing into chamber for up to 33-660s. At the end of oxidation test, argon flow was switched on to prevent from any further oxidation. Finally, the sample was cooled down to ambient temperature at $40^{\circ} \mathrm{C} / \mathrm{s}$. The sample with oxide scale was protected by a spray layer of Lacquer [13] to avoid any other contamination or any spallation before the examination, then was cut into the dimensions $10 \mathrm{~mm} \times 9 \mathrm{~mm} \times 5 \mathrm{~mm}$ using a Struers Accutom-50 cutting machine. 

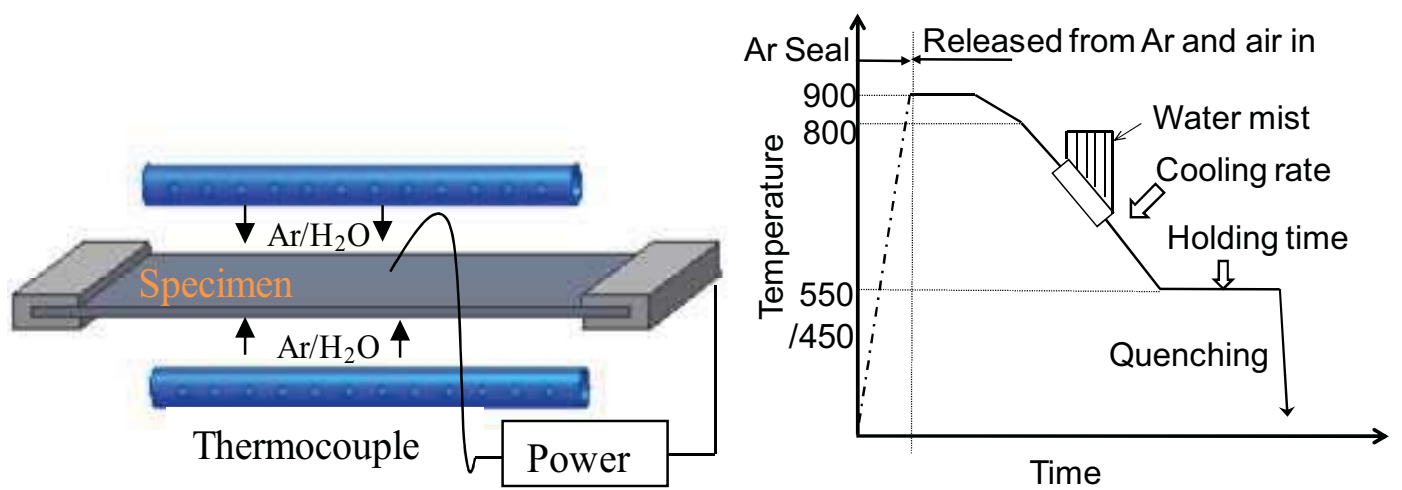

Fig. 3 Illustratration of oxidation test to generate oxide Fig. 4 Thermo-cycle curve for oxidation test in scale in Gleeble 3500

Gleeble 3500

Chemical Analysis. Phase identification of the oxide scale formed on the samples was conducted by GBC MMA advanced thin-film X-ray diffraction (XRD). Then, one of the broad surfaces of samples mounted in epoxy resin is ground by $\mathrm{SiC}$ paper and polished by diamond suspension down to the surface finish of $1 \mu \mathrm{m}$. After that, the etchant consist of a $0.5-1 \%$ hydrochloric acid solution in ethanol was used for the etching of samples [14]. Optical microscope and A JEOL JSM 6490 scanning electron microscope (SEM) were also employed to characterise the microstructure and morphology at the cross-section of the specimen after oxidation.

\section{Results and Discussion}

Determining the temperature range and conditions for magnetite precipitation. Oxide scale formed by air oxidation between 800 and $900^{\circ} \mathrm{C}$ and subsequent humid air oxidation, experienced rapid cooling until the ambient temperature and the isothermal decomposition treatment at temperatures of 550 and $450^{\circ} \mathrm{C}$ for periods from 33-660s. The precipitation behavior of magnetite particles in wustite layer on microalloyed low carbon steel has been studied. It has been observed that the precipitation of magnetite with the formation of metastable wustite enriched with iron at $450^{\circ} \mathrm{C}$. Fig. 5 shows the X-ray patterns of the oxide scales formed at 550 and $450^{\circ} \mathrm{C}$ after holding for $5 \mathrm{~min}$. Comparison of the intensities of magnetite and hematite suggests that both the oxides exist in all the layered oxide scales.
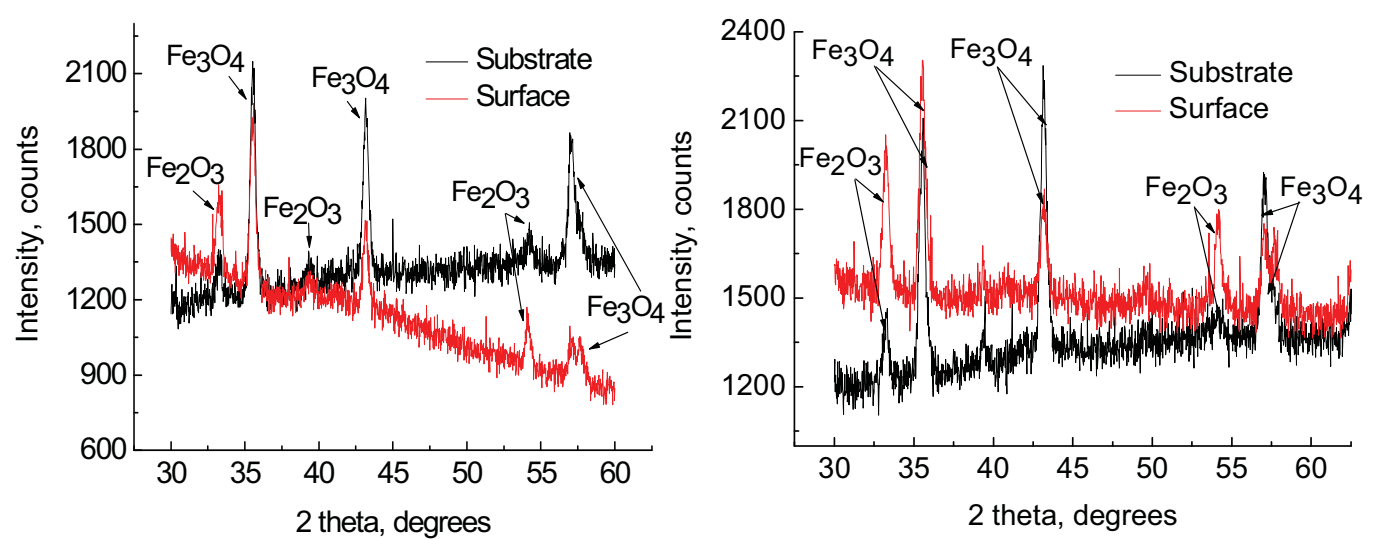

Fig. 5 The X-ray patterns of the oxide scale, a) at $550^{\circ} \mathrm{C}$, b) at $450^{\circ} \mathrm{C}$ holding for $5 \mathrm{~min}$

Compared the two illustrations in Fig. 5, it is interesting to note that the intensification of magnetite phase has a discernibly increase at $450{ }^{\circ} \mathrm{C}$. Furthermore, a steep increase of hematite phase on the surface of oxide scale was also observed. This was possibly due to the disproportioning of wustite into magnetite and iron occurs most rapidly in the temperature range $375-475^{\circ} \mathrm{C}$ [7]. The amount of retained wustite will therefore depend on the cooling rate in this temperature range. Actually, in order to precipitate the magnetite particles from the wustite layer, either the supply of the 
oxygen atoms from the external atmosphere or the eutectoid decomposition should occur [15]. Thus, it is quite possible to achieve the formation of a multi-structure including retain wustite and magnetite or iron precipitates depending on the conditions of its formation [15] and the oxygen content [10].

Precipitation behavior of magnetite particles under cooling process. In most cases, the two-layer microstructure of the samples in this study can be observed: a thin outer layer of hematite, followed by a layer of a mixture of $\alpha$-iron and magnetite. Before etching of the samples, the surface of hematite layer could be clearly identified by its brighter color, as shown in Fig. 6, nevertheless, the magnetite-iron eutectoid could be differentiated from magnetite phase by showing high brightness after etching [14]. Subsequently, the morphology of the oxide scale, scattered iron particles in the magnetite layer and a thin magnetite film adherence to the steel substrate, are also shown in Fig. 6. It can be seen that the particularly well-developed magnetite seam has a heavily serrated edge and some rounded pores, which means that it consists of a continuous row of crystals growing from the interface of the wustite and steel substrate.

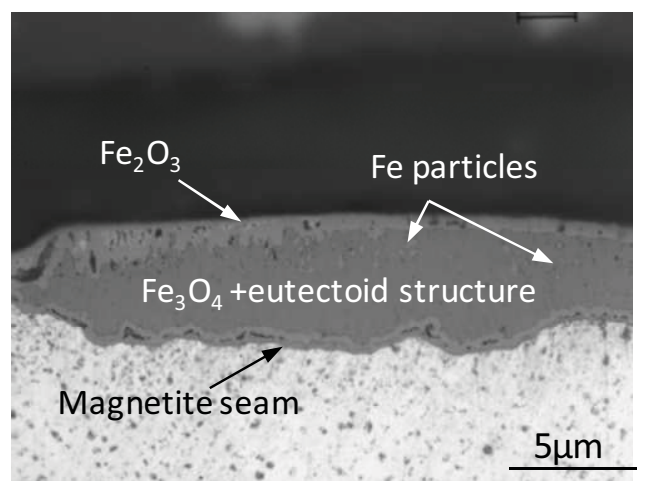

Fig. 6 Scattered iron particles in magnetite layer and a thin magnetite film adherence to substrate

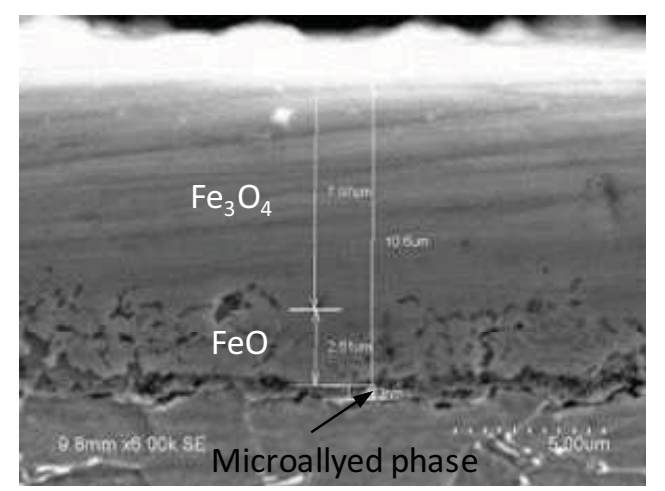

Fig. 7 SEM photograph showing the coarse magnetite seam with mircoalloyed phase

However, the previous examination of the oxide scale on commercial hot-rolled steel strips where the finishing temperature (FT) is $860^{\circ} \mathrm{C}$ and the coiling temperature is $630^{\circ} \mathrm{C}$ [16] reveals the presence of magnetite and iron-rich wustite as shown in Fig. 7, but no iron has been found in any of the oxide layers. Evidently, the cooling rates employed during the laminar cooling after rolling are fast enough to suppress wustite breakdown above $480^{\circ} \mathrm{C}$, but allow it to decompose partially at a lower temperature during off-line cooling of hot coils. In addition, there is some evidence that iron may be precipitated without being detected in the microstructure of the oxide scale. Based on the fact that the iron deficiency across the thickness of the adherent wustite layer increases linearly whilst the immediate vicinity of the steel substrate decreases slightly [8], it can be deduced that the precipitation of iron from the wutite migrate back to the metal surface. As for the microalloyed low carbon steel, the area close to the interface enriches some of the other elements in the steel (also see Fig. 7). These elements might provide added stimulus to lower the stability of wustite, so that it decomposes more readily and facilitates precipitation of magnetite particles.

In principle, the intergrowth of such iron and magnetite is similar to that of the pearlite comprising iron and carbides. The profound difference results from the rate of solution. The component that has to be dispersed by diffusion is relatively mobile in the case of the carbide and virtually incapable of diffusion in the case of the oxide. Thus, the magnetite particles precipitate not by dispersion of oxygen ions but by dilution with iron. Whatever continuous cooling or isothermal treatment, it should be noted that the cooling process is the appreciably dominating factor for the final microstructure and composition of the oxide scale, rather than the oxidation conditions at high temperatures.

Nucleation mechanism of magnetite precipitation. Magnetite particles generated from the wustite layer in the beginning of transformation above $570^{\circ} \mathrm{C}$ imply the significance of the following one-stage decomposition [10] corresponding to the area $\mathrm{A}$ in the $\mathrm{Fe}-\mathrm{O}$ phase diagram (Fig. 1): 


$$
\mathrm{Fe}_{1-x} \mathrm{O} \rightarrow \mathrm{vFe} e_{1-y} \mathrm{O}+(1-v) \mathrm{Fe}_{3} \mathrm{O}_{4}{ }^{\mathrm{I}}
$$

where $x>y, \mathrm{Fe}_{1-\mathrm{y}} \mathrm{O}$ is an iron-rich wustite, $v=\frac{1-4 y}{1-4 x}$.

When the temperature drops to the eutectoid temperature, where multistage low-temperature decomposition is proceeding with area B in Fig. 1, initial wustite is decomposed into metastable stoichiometric wustite (enriched with iron), and oxygen-rich wustite $x>z$ :

$$
\mathrm{Fe}_{1-z} \mathrm{O} \rightarrow \mathrm{FeO}+\mathrm{Fe}_{1-x} \mathrm{O} .
$$

Then, the decomposition of oxygen-rich wustite into stoichiometric wustite and the second magnetite:

$$
\mathrm{Fe}_{1-x} \mathrm{O} \rightarrow \mathrm{vFeO}+(1-v) \mathrm{Fe}_{3} \mathrm{O}_{4}{ }^{I I} .
$$

where Eq. 2 is right, when $\mathrm{y}=0$. Finally, the breakdown of metastable stoichiometric wustite into two equilibrium phases:

$$
4 \mathrm{FeO} \rightarrow \alpha-\mathrm{Fe}+\mathrm{Fe}_{3} \mathrm{O}_{4}{ }^{\mathrm{III}} .
$$

Reaction (4) proceeds rapidly and outstrips reaction (5) to a considerable extent at temperature of maximum decomposition rate in area $\mathrm{B}\left(250\right.$ to $\left.350^{\circ} \mathrm{C}\right)$ [7] during several hours, with the probable result of no visible precipitation of metallic iron.

As mentioned previously, magnetite precipitates by dilution with iron and the diffusion mechanism is illustrated in Fig. 8. The rapid formation of magnetite precipitation first on cooling wustite near to the interface of magnetite and wustite, in part, can be a consequence of the defect structure where has a higher oxygen concentration, until the depleting large amount of oxygen and then to cause iron precipitation. After that, magnetite precipitates at the metal-scale interface where the oxygen content increases and approximates that of corresponding to the eutectoid transformation. Below $475^{\circ} \mathrm{C}$, magnetite presumably nucleates at this same region and propagates as epitaxial intergrowths in the wustite during holding at lower temperature. It is worth to mention that the initial wustite with richer iron is liable to form iron-rich wustite [15], which will result in larger diffusion path, and lower the nucleation growth rate of magnetite particles. Moreover, the diffusion mechanism requires oxide scale without relatively larger defects, such as gaps, blisters or cracks, which would cut off the diffusion path according to solid-state mass transfer theory [1].
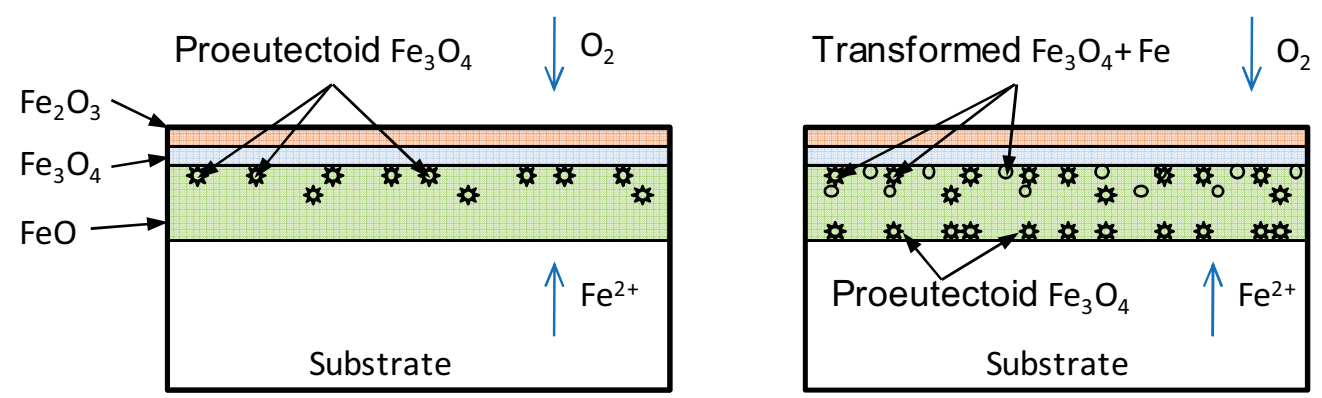

Fig. 8 Diffusion mechanism of magnetite precipitation due to different of oxygen concentration

It is well conceivable that such a spatial arrangement of magnetite and $\alpha$-iron will substantially lead to a very rough interface and thereby enhance the toughness of the oxide scale, and thus its resistance to adhesive failure of the oxide scale. Furthermore, some experiments [8] have verified that the oxide scale has spalled off easily under stresses due to cooling or handling when the precipitation of magnetite and iron particles were absent. Consequently, it is thought that the adhesive force of oxide scale is strong in such a structure where the wustite has completely transformed with a thin top layer and the presence of the magnetite-seam and eutectoid structure. 


\section{Summary}

Precipitation behavior of magnetite particles in oxide scale during isothermal cooling of microalloyed low carbon steel was studied using scanning electron microscopy and thin film X-ray. Several types of precipitates were obtained at different cooling processes, with respect to the possible mechanisms are discussed. Furthermore, possible explanations of the origin of the magnetite seam have been considered in the light of the results presented in this paper. The evidence points to nucleation at the interface of magnetite precipitation from the wustite during cooling process. However, the area near to the interface is known to be enriched in some of the other elements in the mirocalloyed steel. These elements may lower the stability of wustite, so that magnetite particles precipitate more readily near the interface, thereby will appreciably determine the adhesive strength of the oxide scale.

\section{Acknowledgements}

X.L. Yu wishes to thank University of Wollongong for a PhD Grant support. The assistances provided by our colleagues at laboratories, particularly Mr. Bob De Jong, Mr. Greg Tillman and Ms Liang Chen, are sincerely acknowledged.

\section{References}

[1] D. J. Young: High Temperature Oxidation and Corrosion of Metals (Elsevier, Amsterdam, 2008).

[2] M. Krzyzanowski, J.H. Beynon and D.C.J. Farrugia: Oxide Scale Behavior in High Temperature Metal Processing (Wiley-VCH, Darmstadt, 2010).

[3] Z.Y. Jiang, A. K. Tieu, W.H. Sun, J.N. Tang and D.B. Wei: Mat. Sci. Eng. A: Struct., Vol. 435-436 (2006), p. 434.

[4] J. Paidassi: Acta Metall., Vol. 6 (1958), p. 184.

[5] X.L. Yu, Z.Y. Jiang, X.D. Wang, D.B. Wei and Q. Yang: Adv. Mat. Res., Vols. $415-417$ (2012), p. 853.

[6] H.A. Wriedt: in Binary Alloy Phase Diagrams, 2nd edn., edited by T.B. Massalski, H. Okamoto, P.R. Subramanian and L. Kacprzak, volume 2, ASM Intern., Materials Park (1990), p. 1739.

[7] B. Gleeson, S.M. Hadavi and D.J. Young: Mater. High Temp., Vol. 17 (2000), p. 11.

[8] K. Sachs and G.T.F. Jay: J. Iron Steel Inst. (London), Vol. 195 (1960), p. 180.

[9] R.Y. Chen and W.Y.D. Yuen: Oxid. Met., Vol. 53 (2000), p. 539.

[10] J. Baud, A. Ferrier and J. Maneno: Oxid. Met., Vol. 12 (1978), p. 331.

[11] D. B. Wei, J. X. Huang, A. W. Zhang, Z. Y. Jiang, A. K. Tieu, X. Shi and S. H. Jiao: Wear, Vol. 271 (2011), p. 2417.

[12] H. Echsler, S. Ito and M. Schütze: Oxid. Met., Vol. 60 (2003), p. 241.

[13] X.L. Yu, D.B. Wei, Z.Y. Jiang, X.D. Wang: Adv. Mat. Res., Vols.472-475 (2012), p. 622.

[14] R.Y. Chen and W.Y.D. Yuen: ISIJ Int., Vol. 45 (2005), p. 52.

[15] F. Matsuno, Y.Ohmori: Trans. Jpn. Inst. Met., Vol. 29 (1988), p. 8.

[16] D.J. Yang: Technical Report, unpublished, 2010. 


\section{Advances in Rolling Equipment and Technologies II}

10.4028/www.scientific.net/AMR.572

\section{Precipitation Behavior of Magnetite in Oxide Scale during Cooling of Microalloyed Low Carbon Steel}

10.4028/www.scientific.net/AMR.572.249

\section{DOI References}

[1] D. J. Young: High Temperature Oxidation and Corrosion of Metals (Elsevier, Amsterdam, 2008).

doi:10.1016/S1875-9491(08)00003-3

[2] M. Krzyzanowski, J.H. Beynon and D.C.J. Farrugia: Oxide Scale Behavior in High Temperature Metal Processing (Wiley-VCH, Darmstadt, 2010). doi:10.1002/9783527630318

[3] Z.Y. Jiang, A. K. Tieu, W.H. Sun, J.N. Tang and D.B. Wei: Mat. Sci. Eng. A: Struct., Vol. 435-436 (2006), p.434. doi:10.1016/j.msea.2006.07.070

[7] B. Gleeson, S.M. Hadavi and D.J. Young: Mater. High Temp., Vol. 17 (2000), p.11. doi:10.3184/096034000783640776

[9] R.Y. Chen and W.Y.D. Yuen: Oxid. Met., Vol. 53 (2000), p.539.

doi:10.1023/A:1004637127231

[10] J. Baud, A. Ferrier and J. Maneno: Oxid. Met., Vol. 12 (1978), p.331. doi:10.1007/BF00603577

[11] D. B. Wei, J. X. Huang, A. W. Zhang, Z. Y. Jiang, A. K. Tieu, X. Shi and S. H. Jiao: Wear, Vol. 271 (2011), p.2417.

doi:10.1016/j.wear.2010.11.029

[12] H. Echsler, S. Ito and M. Schütze: Oxid. Met., Vol. 60 (2003), p.241. doi:10.1023/A:1026067118621

[14] R.Y. Chen and W.Y.D. Yuen: ISIJ Int., Vol. 45 (2005), p.52. doi:10.2355/isijinternational.45.52 